\title{
Breeding of Brassica rapa for Biogas Production: Heterosis and Combining Ability of Biomass Yield
}

\author{
Atta Ofori • Heiko C. Becker
}

Published online: 4 March 2008

(C) The Author(s) 2008

\begin{abstract}
The use of plant biomass as substrate for biogas production has recently become of major interest in Europe. Winter Brassica rapa produces high early biomass and could be grown as a pre-crop harvested early in the year followed by a second crop such as maize. The objectives of this study were to estimate heterosis and combining ability of 15 European winter B. rapa cultivars for biomass yield at end of flowering. A half-diallel without reciprocals was conducted among cultivars to produce 105 crosses. These crosses and their parents were evaluated in two years at two locations in Northern Germany. Data collected were days to flowering (DTF), fresh biomass yield (FBY), dry matter content (DMC) and dry biomass yield (DBY). The mean DBY was $5.3 \mathrm{t} / \mathrm{ha}$ for the parental cultivars and $5.6 \mathrm{t} / \mathrm{ha}$ for their crosses. The crosses surpassed on average their parents by $7.6 \%$ for FBY and $5.9 \%$ for DBY whereas DMC was $1.4 \%$ higher in the parents. Maximum mid parent heterosis was $21.0 \%$ for FBY and $30.4 \%$ for DBY. Analysis of variance showed that genetic variance was mainly due to specific combining ability (SCA). The correlation between parental performance and general combining ability (GCA) was $0.42 * *$ for FBY and $0.53 * *$ for DBY. In conclusion, the amount of heterosis in crosses between European winter $B$. rapa cultivars is not very high on average, but can be up to $30 \%$ in the best crosses. Selection of parental combinations with high specific combining ability to produce synthetic cultivars can rapidly improve biomass yield.
\end{abstract}

Keywords Biogas · Diallel · Full-sibs · General combining ability $\cdot$ Synthetic cultivars $\cdot$ Specific combining ability

\footnotetext{
A. Ofori $(\bowtie) \cdot$ H. C. Becker

Georg-August-University Göttingen,

Göttingen, Germany

e-mail: ofori77@yahoo.com
}

\section{Introduction}

Different technologies to convert biomass to bioenergy have been developed and among them biogas production has gained major interest in the past years in Europe. The number of biogas plants operating in Germany at the end of 2006 was 3.500 [22], an increased of $75 \%$ between 2004 and 2006. Presently, over 350.000 ha, representing $2 \%$ of agricultural land in Germany is used for the cultivation of biogas energy crops. However, about $80 \%$ of the biogas substrate in Germany comes from maize [22], a crop of sub-tropical origin with low cold tolerance that can not be sown before May, and is harvested in September/October.

For maximum utilisation of land and availability of biogas substrate through out the year, biomass crops that are winter hardy and can be harvested early in the year are required. This will give growers the option to grow two crops in one season: the first one sown in autumn and harvested in spring, followed by a second crop adapted to higher temperatures like maize, sorghum or sunflower [16]. Crops with high biomass production at low temperature are rye, some forage grasses, and also Brassica crops. Among the Brassicas, B. rapa is of special interest, because it has a higher early biomass and flowers earlier than B. napus $[9,15]$.

Today, $B$. rapa is mainly grown as spring oilseed crop in Canada and some marginal regions in Northern Europe. Traditionally, winter B. rapa was also grown as winter oilseed crop in Northern and Central Europe, but the cultivation has nearly ceased. However, there is a renewed interest in the cultivation of winter B. rapa in Europe to produce biomass, because of its high growth rate at low temperature in early spring. Harvest of biomass could be at end of flowering when biomass yield has nearly reached its maximum [3].

For biomass production, also older cultivars of winter $B$. rapa can be used. They have sometimes low grain yield and 
relatively poor seed quality which is of little relevance for biomass production. Also, this could contribute to increased biodiversity.

B. rapa is a cross-pollinated and self-incompatible crop with high genetic diversity within cultivars [25]. Different methods such as full-sib selection or the development of synthetic cultivars have been exploited in Brassica population improvement (for review see [2]). Among these methods, full sib selection makes direct use of combing ability and heterosis [11] and utilizes both within and between family genetic variation [1]. Lamkey and Edwards [12] suggested the term "panmictic mid parent heterosis" for the difference between the mean of two random mating populations and the mean of a hybrid population produced by crossing individual plants of the two populations.

A number of studies on combing ability and heterosis for yield and yield components have been carried out. Singh and Murty [18] in B. rapa subspecies yellow sarson observed predominance of non additive genetic effects. Wang et al. [21] among different subspecies of B. rapa observed the importance of general combining ability and specific combining ability in controlling different traits. Yadav et al. [23] in nine inbred lines of brown sarson used as females and three other cultivars as males observed large specific combining ability for plant height, number of branches per plant, number of seed per pot, 1,000-seed weight and seed yield per plant.

Schuler et al. [17] in inter-cultivar $\mathrm{F}_{1} \mathrm{~s}$ of $B$. rapa reported mid parent heterosis (MPH) of $18 \%$ for seed yield and Falk et al. [6] in inter-cultivar of spring B. rapa reported heterosis of $13 \%$ for seed yield. Kaur et al. [10] in B. rapa subspecies toria, brown sarson and yellow sarson observed $31 \%$ heterosis in intra group crosses and $17 \%$ in inter group crosses for seed yield. Wang et al. [21] in Chinese B. rapa vegetables reported MPH of $10 \%$ for plant leaves, $44 \%$ for petiole fresh weight and $17 \%$ for the length of biggest leaf.

The aim of this study is to analyse the genetics of biomass yield of 15 winter $B$. rapa cultivars and F1s derived from crosses amongst them. The specific objectives were: (1) to evaluate the biomass yield during flowering, (2) to estimate the effects of general and specific combining ability (GCA and SCA), and (3) to estimate the magnitude of heterosis in population crosses. The results will allow the development of efficient breeding strategies for B. rapa as new bioenergy crop in Europe.

\section{Materials and Methods}

Plant Materials The plant materials used in this experiment consisted of 15 winter B. rapa cultivars of European origin. Seeds were obtained from either genebanks or breeding companies (Table 1). The cultivars are from different geographical regions within Europe and their seed quality differs with respect to erucic acid and seed glucosinolate content.

Full-sib Development The 15 winter B. rapa cultivars were crossed in half-diallel manner without reciprocals in May 2005 and 2006. In each year, three full sibs (FS) were produced from each of the 105 parental combinations by isolating two plants under one large bag before begin of flowering.

Field Evaluation For evaluation, equal amounts of seed from the three FS of each combination were bulked. The 15

Table 1 Brassica rapa cultivars used in this study with their country of origin

\begin{tabular}{lllll}
\hline Cultivar name & Country of origin & Seed quality & Sources/breeder & Accession number \\
\hline Steinacher & Germany & ++ & BAZ, Braunschweig, Germany & BAZ 18101 \\
Weibulls Storrybs & Sweden & ++ & CZ, Czechoslovakia & BRA 245 \\
BRA 245 & Bulgaria & ++ & IPK, Gatersleben, Germany & BAZ 34349 \\
Lemkes Winter & Germany & ++ & BAZ, Braunschweig, Germany & BAZ 34342 \\
Lemkes Malchower & Germany & ++ & BAZ, Braunschweig, Germany & BAZ 34354 \\
Arktus & Germany & ++ & BAZ, Braunschweig, Germany & BRA 11 \\
Schneiders Sprengel & Germany & ++ & IPK, Gatersleben, Germany & BAZ 34335 \\
Hege's Winter & Germany & ++ & BAZ, Braunschweig, Germany & BAZ 31204 \\
Janetzki's & Germany & ++ & BAZ, Braunschweig, Germany & BAZ \\
Opava & Czechoslovakia & ++ & BAZ, Braunschweig, Germany & BAZ 34346 \\
Grubes Winter & Germany & ++ & BAZ, Braunschweig, Germany & - \\
Wild collection & Germany & ++ & Bonn, Germany & - \\
Orbit & Sweden & $0+$ & SW Seed, Sweden & - \\
Largo & Sweden & 00 & SW Seed, Sweden & NPZ, Germany \\
Rex & Germany & $0+$ & & \\
\hline
\end{tabular}

${ }^{\mathrm{a}}++$ High erucic acid, high glucosinolate, $0+$ zero erucic acid, high glucosinolate, 00 zero erucic acid, low glucosinolate

${ }^{\mathrm{b}}$ By courtesy of the collector Thomas Gladis, University of Kassel, Germany 
Table 2 Minimum, maximum, mean, least significant difference (LSD) for 15 winter B. rapa cultivars and their 105 diallel crosses across four environments

\begin{tabular}{|c|c|c|c|c|c|c|c|}
\hline \multirow[t]{2}{*}{ Traits } & \multicolumn{3}{|l|}{ Parents } & \multicolumn{3}{|c|}{ Crosses } & \multirow[t]{2}{*}{$\operatorname{LSD}(5 \%)$} \\
\hline & Min & $\operatorname{Max}$ & Mean & Min & Max & Mean & \\
\hline DTF (days) & 233.0 & 238.3 & 236.0 & 232.7 & 238.3 & 235.8 & 2.1 \\
\hline DMC (\%) & 13.7 & 17.3 & 15.3 & 12.9 & 16.9 & 15.1 & 2.3 \\
\hline $\mathrm{FBY}\left(\mathrm{kg} / \mathrm{m}^{2}\right)$ & 3.1 & 3.9 & 3.5 & 3.3 & 4.3 & 3.8 & 0.5 \\
\hline DBY $\left(\mathrm{g} / \mathrm{m}^{2}\right)$ & 477.2 & 605.2 & 530.6 & 442.7 & 666.4 & 561.3 & 105.5 \\
\hline
\end{tabular}

$D T F$ days to flowering, $D M C$ dry matter content, $F B Y$ fresh biomass yield, $D B Y$ dry biomass yield

parental cultivars, their 105 crosses, and a check cultivar 'Perko' were grown in two years at the two locations Göttingen and Einbeck in Northern Germany. The FS produced in 2005 were tested in 2005/2006, the FS produced in 2006 were tested in 2006/2007. The experimental design was an $11 \times 11$ lattice with two replicates.

Sowing dates were 24th of August at Einbeck and 31st of August at Göttingen in 2005, and 31st of August at Einbeck and 5th of September at Göttingen in 2006. Rate of sowing was between 90 and 110 seeds $/ \mathrm{m}^{2}$. Plot size in Göttingen was $11.25 \mathrm{~m}^{2}$ and each plot consisted of six rows, $7.5 \mathrm{~m}$ long and $0.25 \mathrm{~m}$ between rows. In Einbeck, plot size was $9 \mathrm{~m}^{2}$ and plots consisted of six rows, $5 \mathrm{~m}$ long and $0.3 \mathrm{~m}$ between rows. Standard crop management practices for weed control and fertilization were followed.

Data were recorded on days to flowering (from the day of sowing until $50 \%$ of plants were flowering), fresh biomass yield $\left(\mathrm{kg} / \mathrm{m}^{2}\right)$, dry matter content $(\%)$ and dry biomass yield $\left(\mathrm{g} / \mathrm{m}^{2}\right)$. Plots were harvested on the 8 th of
May at Einbeck and 15th of May at Göttingen in 2006, and 2nd of May at Einbeck and 21st of May at Göttingen in 2007. The growth stage at that time was end of flowering. Harvesting was done with a harvester that cut plants at $5 \mathrm{~cm}$ above ground and the total fresh biomass yield was measured. From each plot a sample of $300 \mathrm{~g}$ fresh weight was dried at $60^{\circ} \mathrm{C}$ for 6 days to determine the dry matter content and to calculate the dry biomass yield per plot.

Statistical Analysis Analyses of variance (ANOVA) were first run separately for each experiment using PLABSTAT software [19]. A combined analysis of variance of the adjusted means was then computed over the four environments. Random effects model was assumed. The sum of squares for entry effects were partitioned into parents, crosses and parents vs. crosses effects. The variance of crosses was further partitioned into GCA and SCA, according to analyses III of Gardner and Eberhart [8] using PZ14 software [20].

Table 3 Mean squares (MS) and variance components (Vc) from combined analysis of variance for 15 winter $B$. rapa cultivars and their 105 diallel crosses over four environments

\begin{tabular}{|c|c|c|c|c|c|c|c|c|c|}
\hline \multirow[t]{2}{*}{ Source } & \multirow[t]{2}{*}{$d f$} & \multicolumn{2}{|l|}{ DTF (days) } & \multicolumn{2}{|l|}{ DMC (\%) } & \multicolumn{2}{|c|}{ FBY $\left(\mathrm{kg} / \mathrm{m}^{2}\right)$} & \multicolumn{2}{|l|}{$\operatorname{DBY}\left(\mathrm{g} / \mathrm{m}^{2}\right)$} \\
\hline & & MS & $\mathrm{Vc}$ & MS & $\mathrm{Vc}$ & MS & $\mathrm{Vc}$ & MS & $\mathrm{Vc}$ \\
\hline Environment (E) & 3 & $25,533.23 * *$ & 212.8 & $1,460.75^{* *}$ & 12.14 & $12.80 * *$ & 0.106 & $2,356,116^{* *}$ & $19,586.35$ \\
\hline Genotypes & 119 & $5.91 * *$ & 0.934 & 3.05 & 0.05 & $0.20 * *$ & 0.023 & $8,373.36^{* *}$ & 654.78 \\
\hline Parents & 14 & $9.79 * *$ & 1.781 & 3.90 & 0.149 & 0.14 & 0.045 & $4,998.32$ & $0^{\mathrm{a}}$ \\
\hline Parent vs crosses & 1 & 0.87 & & 2.79 & & $3.57 * *$ & & $49,722.04 * *$ & \\
\hline Crosses & 104 & $5.44 * *$ & 0.831 & 2.93 & 0.048 & $0.17 * *$ & 0.017 & $8,430.11 * *$ & 717.78 \\
\hline GCA & 14 & $24.92 * *$ & 0.358 & $5.48 *$ & 0.061 & $0.35 *$ & 0.004 & $9,496.28$ & 9.209 \\
\hline SCA & 90 & $2.41 * *$ & 0.205 & 2.54 & 0 & $0.16^{*}$ & 0.011 & $8,264.27 * *$ & 701.66 \\
\hline $\mathrm{G} \times \mathrm{E}$ & 357 & $2.18^{* *}$ & 1.500 & $2.83 * *$ & 1.000 & $0.11 * *$ & 0.053 & $5,754.21 * *$ & $3,123.23$ \\
\hline Parent $\times E$ & 42 & $2.67 * *$ & 1.999 & $3.30 * *$ & 1.468 & $0.12 * *$ & 0.070 & $6,302.84 * *$ & $3,671.86$ \\
\hline Parent vs crosses $\times \mathrm{E}$ & 3 & $5.61 * *$ & & $16.52 * *$ & & $0.45 * *$ & & $55,131.32 * *$ & \\
\hline Crosses $\times \mathrm{E}$ & 312 & $2.11 * *$ & 1.44 & $2.74 * *$ & 0.910 & $0.10 * *$ & 0.049 & $5,558.98 * *$ & $2,927.00$ \\
\hline $\mathrm{GCA} \times \mathrm{E}$ & 42 & $5.48 * *$ & 0.300 & 2.56 & 0 & 0.12 & 0.002 & $6,210.163$ & 57.92 \\
\hline $\mathrm{SCA} \times \mathrm{E}$ & 270 & $1.59 * *$ & 0.915 & $2.77 * *$ & 0.938 & $0.10 * *$ & 0.047 & $5,457.61 * *$ & 2,826 \\
\hline Error & 390 & 0.67 & & 1.83 & & 0.05 & & $2,630.98$ & \\
\hline
\end{tabular}

$D T F$ Days to flowering, $D M C$ dry matter content, $F B Y$ fresh biomass yield, $D B Y$ dry biomass yield

$*, * *$ Significantly different from 0 at $P=0.05$ and $P=0.01$, respectively

${ }^{a}$ Negative estimates of variance component 
Table 4 Minimum, maximum, mean and standard error (SE) for relative mid parent heterosis (MPH\%) and relative high parent heterosis (HPH\%) for 105 crosses of winter B. rapa cultivars over four environments

\begin{tabular}{|c|c|c|c|c|c|c|c|c|}
\hline \multirow[t]{2}{*}{ Traits } & \multicolumn{4}{|l|}{ МРH\% } & \multicolumn{4}{|l|}{ НPH\% } \\
\hline & Min. & Max. & Mean & SE & Min. & Max. & Mean & $\mathrm{SE}$ \\
\hline DTF & -0.93 & 1.09 & -0.05 & 0.04 & -1.95 & 1.06 & -0.43 & 0.05 \\
\hline DMC & -16.63 & 13.52 & -1.42 & 0.56 & -18.25 & 8.04 & -4.78 & 0.61 \\
\hline FBY & -8.04 & 21.02 & 7.56 & 0.62 & -9.19 & 20.85 & 4.37 & 0.62 \\
\hline DBY & -15.24 & 30.41 & 5.93 & 0.88 & -18.75 & 28.03 & 2.10 & 0.89 \\
\hline
\end{tabular}

$D T F$ Days to flowering, $D M C$ dry matter content, $F B Y$ fresh biomass yield, $D B Y$ dry biomass yield

Heterosis was calculated as follows: relative mid parent heterosis $\mathrm{MPH} \%=($ Crosses $-\mathrm{MP}) / \mathrm{MP} \times 100$ and relative high parent heterosis $(\mathrm{HPH} \%)=($ Crosses $-\mathrm{HP}) / \mathrm{HP} \times 100$, where MP is mid-parent and HP is high parent. To test for significant differences in heterosis, analysis of variance (ANOVA) was performed for $\mathrm{MPH} \%$ and $\mathrm{HPH} \%$ values.

\section{Results}

The mean biomass yield over two years and two locations were higher in the crosses than in the parents (Table 2). The crosses out yielded the parents for fresh biomass yield (FBY) by $0.3 \mathrm{~kg} / \mathrm{m}^{2}(7.5 \%)$ and for dry biomass yield (DBY) by $30.7 \mathrm{~g} / \mathrm{m}^{2}$ (5.8\%). Dry matter content (DMC) was $0.2 \%$ higher in the parents. Days to flowering (DTF) were nearly the same in the crosses and the parents. The differences between maximum and minimum values were low for DTF but relatively higher for DMC, DBY and FBY. The parents with highest DBY were Opava $\left(605 \mathrm{~g} / \mathrm{m}^{2}\right)$, Arktus $\left(576 \mathrm{~g} / \mathrm{m}^{2}\right)$ and Lembkes Malchower $\left(554 \mathrm{~g} / \mathrm{m}^{2}\right)$, the highest yielding crosses were Orbit $\times$ Lembkes Winter $\left(666 \mathrm{~g} / \mathrm{m}^{2}\right)$, Orbit $\times$ Opava $\left(665 \mathrm{~g} / \mathrm{m}^{2}\right)$ and Orbit $\times$ Arktus $\left(657 \mathrm{~g} / \mathrm{m}^{2}\right)$.

The combined ANOVA pooled over four environments showed highly significant variation among environments for all traits (Table 3). Significant differences among genotypes were observed for all traits accept DMC and genotype $\times$ environments were significant for all traits.
Partitioning of genotypes into parents and crosses showed significant variation of the parents only for DTF whereas the variation of parents $\times$ environments were highly significant for all traits. The variances due to crosses were significant for all traits except DMC and their interactions with environments were highly significant for all traits. The effect of parents vs crosses, indicating the presence of heterosis, was significant for FBY and DBY, and parent vs crosses $\times$ environments were highly significant for all traits.

Partitioning of the variance among crosses into GCA and SCA gave different results for different traits. For DTF and DMC the variance component for GCA was larger than for SCA, whereas for FBY and DBY the SCA was of larger importance. The GCA significantly interacted with environments only for DTF and the SCA showed highly significant interactions with environment for all traits.

The MPH\% and $\mathrm{HPH} \%$ estimates varied for the different traits over environments (Table 4). Heterosis was observed for FBY and DBY but not for DMC. The small negative estimate for DTF means that flowering was earlier in the crosses compared to their parents. The effects of heterosis were generally low; for FBY the average mid parent heterosis (MPH) was $7.6 \%$, ranging from -8.0 to 21.0 , and for DBY the average MPH was $5.9 \%$, ranging from -15.2 to 30.4 . The average high parent heterosis (HPH) was $4.4 \%$ for FBY and $2.1 \%$ for DBY.

Analysis of variance for MPH\% and $\mathrm{HPH} \%$ (Table 5) showed significant variation among environments for both $\mathrm{MPH} \%$ and $\mathrm{HPH} \%$. The variation among crosses was

Table 5 Mean squares of analysis of variance for relative mid parent heterosis (MPH\%) and relative high parent heterosis (HPH\%) for 105 crosses of winter B. rapa cultivars across four environments

\begin{tabular}{|c|c|c|c|c|c|c|c|c|c|}
\hline \multirow[t]{2}{*}{ Source } & \multirow[t]{2}{*}{$d f$} & \multicolumn{4}{|l|}{$\% \mathrm{MPH}$} & \multicolumn{4}{|l|}{$\% \mathrm{HPH}$} \\
\hline & & DTF & $\mathrm{DMC}$ & FBY & DBY & DTF & $\mathrm{DMC}$ & FBY & DBY \\
\hline Environment (E) & 3 & $2.65 * * *$ & $1,078 * * *$ & $852 * * *$ & $3,315 * * *$ & $3.51 * * *$ & $3,663 * * *$ & $323.7^{*}$ & $6,568.7 * * *$ \\
\hline Crosses (C) & 104 & $0.64 * * *$ & 114.22 & 162.01 & 283.36 & $0.98 * * *$ & 119.57 & 140.66 & 263.66 \\
\hline $\mathrm{C} \times \mathrm{E}$ & 312 & $0.35^{* * *}$ & $144.06^{* *}$ & $138.83 * * *$ & $268.85^{* * *}$ & $0.44 * * *$ & 138.43 & $128.8 * * *$ & $238.6^{* * *}$ \\
\hline Error & 390 & 0.18 & 116.89 & 67.24 & 140.36 & 0.24 & 146.48 & 84.85 & 174.28 \\
\hline
\end{tabular}

$D T F$ Days to flowering, $D M C$ dry matter content, $F B Y$ fresh biomass yield, $D B Y$ dry biomass yield $*, * *, * *$ Significantly different from 0 at $P=0.10, P=0.05$ and $P=0.01$, respectively 
Table 6 Correlation coefficients between general combining ability (GCA) and parent value (PV), performance of crosses and mid parent value (MPV), relative mid parent heterosis $(\mathrm{MPH} \%)$ and $\mathrm{MPV}, \mathrm{MPH} \%$ and performance of crosses of winter B. rapa over four environments

\begin{tabular}{lllll}
\hline Traits & $\begin{array}{l}\text { GCA vs } \\
\text { PV }\end{array}$ & $\begin{array}{l}\text { Crosses vs } \\
\text { MPV }\end{array}$ & $\begin{array}{l}\text { MPH\% vs } \\
\text { MPV }\end{array}$ & $\begin{array}{l}\text { MPH\% vs } \\
\text { crosses }\end{array}$ \\
\hline DTF & $0.83^{* *}$ & $0.65^{* *}$ & $-0.29 * *$ & $0.53^{* *}$ \\
DMC & $0.69^{* *}$ & $0.34^{* *}$ & $-0.41^{* *}$ & $0.72^{* *}$ \\
FBY & $0.42^{* *}$ & $0.22^{*}$ & $-0.37 * *$ & $0.83^{* *}$ \\
DBY & $0.53^{* *}$ & $0.21^{*}$ & $-0.29^{* *}$ & $0.87 * *$ \\
\hline
\end{tabular}

$D T F$ Days to flowering, $D M C$ dry matter content, $F B Y$ fresh biomass yield, $D B Y$, dry biomass yield

*, **Significantly different from 0 at $P=0.05$ and $P=0.01$, respectively

significant only for DTF, and the crosses $\times$ environment interactions were significant for all traits.

The correlations between GCA and parent were positive and highly significant for all traits (Table 6). The correlations between crosses and parents were also always positive and significant. However, correlations between mid parents value and $\mathrm{MPH} \%$ were significantly negative for all traits. The correlations between MPH\% and crosses were positive and significant for all the traits, ranging from $r=$ $0.53 * *$ for DTF to $r=0.87 * *$ for DBY.

Correlations among traits were significantly positive between DBY and DMC and DBY and FBY over the environments (Table 7). The DMC was negatively correlated with both FBY and DTF.

\section{Discussion}

The crosses surpassed on average their parents for FBY and DBY indicating the presence of heterosis (Table 2). However, mid parent heterosis was only $7.6 \%$ for FBY and $5.9 \%$ for DBY. This observation was not unexpected since parents used in the study were not chosen on the basis of genetic relatedness but rather geographical regions (Germany, Sweden, Czechoslovakia, and Bulgaria), and the extent of heterosis is influenced by the level of genetic distances between parents [4]. A much higher heterosis for B. rapa grain yield has been reported with 18 [17] and $13 \%$ [6]. However, all these experiments were conducted with spring type $B$. rapa, which might show a higher genetic diversity.

The gene pool of European winter oilseed B. rapa is narrow [24]. When analyzing the diversity of 32 plants each of three cultivars Rex, Largo and Steinacher with molecular markers, we observed most of the variation within populations and only a relatively small part of the variation between populations (unpublished results). This can explain the relative low amount of heterosis observed in crosses between different cultivars, because the parental populations are already highly heterozygous. This may also explain the negative correlation between parental value and MPH. The higher the parental value is, the lesser is the amount of heterosis already utilized within the parental populations, and the smaller is the MPH observed in crosses between populations.

Variations in heterosis were low (Table 5) and significant only for DTF. The possible explanation may be the very high crosses $\times$ environment interactions. A random model was used for the analyses due to which the different components were tested against their environment $\times$ genotype interactions. If a fixed model would have been used, the genotypes would have been tested against the error. In that case, more sources of variation would have become significant. However, to get results that can be generalized, the more conservative tests using a random model were chosen.

It has to be mentioned that the genotype environment interactions are overestimated, because in the two different years three different FS of each cross were used. So each parental population was represented by only six plants. Therefore, a more detailed analysis of the most promising populations with a larger number of FS tested at a larger number of environments is desirable.

The experiment showed that the genetic variance is mainly due to variation in specific combining ability (SCA), indicating the predominance of non additive gene action and the importance of specific cross combinations. This is in agreement with the observation that in specific crosses heterosis can be up to $30 \%$ for DBY. The three crosses with the highest biomass yield were always between cultivars from different European countries. Further improvements in yield can therefore be made by identifying specific high yielding crosses among good combiners. To select parents with high general combining ability (GCA), the always positive correlation between GCA and parental performance can be helpful.

The lower crosses $\times$ environment variance compared to the parents $\times$ environment variance for most traits (Table 3 )

Table 7 Correlation coefficient between four traits of winter B. rapa across four environments

\begin{tabular}{lcrc}
\hline & DMC & FBY & \multicolumn{1}{c}{ DBY } \\
\hline DTF & $-0.31^{* *}$ & 0.04 & $-0.22^{*}$ \\
DMC & & -0.16 & $0.59 * *$ \\
FBY & & & $0.57 * *$ \\
\hline
\end{tabular}

$D T F$ Days to flowering, $D M C$ dry matter content, $F B Y$ fresh biomass yield, $D B Y$ dry biomass yield

*, **Significantly different from $0 P=0.05$ and $P=0.01$, respectively 
agrees with the philosophy, that hybrids are more stable than parents. However, Singh and Murty [18] in B. rapa observed a higher crosses $\times$ environment variance compared to the parents $\times$ environment and concluded, that stability of a cultivar is influenced not only by heterozygosity.

The correlations among traits are important for selection. There were no or only small correlations between flowering time and FBY and DBY, indicating that selection for early flowering will not necessarily improve biomass yield. The correlation between FBY and DBY over environments was only $0.57^{* *}$, which is much lower than the value of $0.95^{* *}$ reported in intersepecific crosses of $B$. rapa $\times$ B. napus by Liu et al. [13]. When analyzing the environments separately (data not shown), we observed low and non significant in one of the environments. Probably there was a technical problem with taking a representative sample of leaves and stem for DMC determination. This problem may partly explain the positive correlation between DMC and DBY.

B. rapa is a diploid species, but tetraploid cultivars have also been developed. For comparison, we included the tetraploid German cultivar "Perko" in the experiments. This cultivar had a FBY of $4.42 \mathrm{~kg} / \mathrm{m}^{2}$ and a DBY of $600 \mathrm{~g} / \mathrm{m}^{2}$. These yields are only surpassed by one of the parents and by seven of the crosses for FBY and 21 for DBY. Future winter B. rapa biomass breeding programmes should therefore consider also the potential of tetraploid genotypes.

In conclusion, the high importance of SCA implies that identifying the best combinations among parents is an efficient way to increase biomass yield. The production of hybrid cultivars will be probably too expensive at the moment, due to the self incompatibility of $B$. rapa and the lack of an easily available hybridizing system. However, as suggested by Falk et al. [7] large quantities of seed can be produced by the approach of synthetic cultivars when different parents are mixed and propagated under open pollination.

When starting with two populations, the first generation after random mating should theoretically be composed of $25 \%$ each of plants from crosses within the parental populations and of $50 \%$ of plants from crosses between the two populations. Synthetic cultivars of $B$. rapa can have nearly the same yield as hybrids [7]. The first synthetic cultivars for oilseed B. rapa were Hysyn 100 and Hysyn 110 released in Canada in 1994 [5]. Also Niemelä et al. [14] observed a yield advantage of up to $18 \%$ in synthetics compared to open pollinated cultivars. Similar approaches could also be successful for breeding B. rapa cultivars for biomass production.
Acknowledgements This project is being financially supported by KWS Saat AG, Einbeck and FNR (Agency for Renewable Resources) Germany. Many thanks also go to Gerald Miotke and colleagues for taking care of the field activities.

Open Access This article is distributed under the terms of the Creative Commons Attribution Noncommercial License which permits any noncommercial use, distribution, and reproduction in any medium, provided the original author(s) and source are credited.

\section{References}

1. Aastveit AH, Aastveit K (1990) Theory and application of openpollination and polycross in forage grass breeding. Theor Appl Genet 79:618-624

2. Becker HC, Löptien H, Röbbelen G (1999) Brassica: an overview. In: Gomez-Campo C (ed) Biology of Brassica Coenospecies. Elsevier, Amsterdam, pp 413-460

3. Diepenbrock W (2000) Yield analysis of winter oilseed rape (Brassica napus L.): a review. Field Crops Res 67:35-49

4. Falconer DS, Mackay TFC (1996) Introduction to quantitative genetics (4th edn.). Longman, England

5. Falk KC, Stoenescu FM (1996) Hysyn 100 summer turnip rape. Can J Plant Sci 76:127-130

6. Falk KC, Rakow GFW, Downey RK, Spurr DT (1994) Performance of inter-cultivar summer turnip rape hybrids in Saskatchewan. Can J Plant Sci 74:441-445

7. Falk KC, Rakow GFW, Downey RK (1998) The utilization of heterosis for seed yield in hybrid and synthetic cultivars of summer turnip rape (B. rapa L.). Can J Plant Sci 78:383-387

8. Gardner CO, Eberhart SA (1966) Analysis and interpretation of the variety cross diallel and related populations. Biometrics 22:4439-4452

9. Halfhill MD, Therland JP, Moon HS, Poppy GM, Warwick SI, Weissinger AK, Rufty TW, Raymer PL, Stewart CN (2005) Growth, productivity, and competitiveness of introgressed weedy Brassica rapa hybrids selected for the presence of Bt crylAc and gfp transgenes. Mol Ecol 14:3177-3189

10. Kaur G, Bansal P, Kaur B, Banga S (2007) Genetic diversity and its association with heterosis in Brassica rapa. In: Proceedings of the 12th international Rapeseed Congress, 26-30 June 2007, Wuhan, China Vol I, pp 144-146

11. Lambeth C, Lee BC, O'Malley D, Wheeler N (2001) Polymix breeding with parental analysis of progeny: an alternative to fullsib breeding and testing. Theor Appl Genet 103:930-943

12. Lamkey KR, Edwards JW (1999) The quantitative genetics of heterosis. In: Coors JG, Pandey S (ed) Proceedings of the International Symposium on the Genetics and Exploitation of Heterosis in Crops, CIMMYT, Mexico City, Mexico, 17-22 Aug. 1997. ASA, CSSA, and SSSA, Madison, WI, pp 31-48

13. Liu R, Qian W, Meng J (2002) Association of RFLP markers and biomass heterosis in trigenomic hybrids of oilseed rape (Brassica napus $\times$ B. campestris $)$. Theor Appl Genet 105:1050-1057

14. Niemelä T, Seppänen M, Jauhianen L, Tulisalo U (2006) Yield potential of spring turnip rape synthetics and composite hybrids compared with open-pollinated commercial cultivars. Can J Plant Sci 86:693-700 
15. Pertl M, Hauser TP, Damgaard C, Jørgensen RB (2002) Male fitness of oilseed rape (Brassica napus), weedy B. rapa and their F1 hybrids when pollinating $B$. rapa seeds. Heredity 89:212-218

16. Scheffer K (1998) Ein produktiver, umweltschonendes Ackernutzungskonzept zur Bereitellung von Energie und Wertstoffen aus der Vielfalt der Kulturpflanzen. Beitr. Akad. Natur Umweltschutz Baden Wüttemberg 27:65-80

17. Schuler TJ, Hutcheson DS, Downey RK (1992) Heterosis in intervarietal hybrids of summer turnip rape in Western Canada. Can J Plant Sci 72:127-136

18. Singh JN, Murty BR (1980) Combining ability and maternal effects in Brassica campestris variety yellow sarson. Theor Appl Genet 56:265-272

19. Utz HF (2001) PLABSTAT: a computer program for the statistical analysis of plant breeding experiments. Version 2P. Institute of Plant Breeding, Seed Science and Population Genetics, University of Hohenheim Stuttgart, Germany

20. Utz HF (1992) PZ14: programm zur Verrechnung dialleler Kreuzungsanlagen über Orte und Jahre. Institute of Plant
Breeding, Seed Science and Population Genetics, University of Hohenheim Stuttgart, Germany

21. Wang J, Wang X, Zhang Y, Zhang Z, Tian Y, Li D (2007) Study on heterosis among subspecies or varieties in $B$ campestris $\mathrm{L}$. In: Proceedings of the 12th International Rapeseed Congress, 26-30 June 2007, Wuhan, China Vol I, pp 108-110

22. Weiland P (2007) Country updates on biogas, Germany. Presentation at the 7th meeting of IEA Bioenergy Task 37 workshop Berlin. Available at: www.iea-biogas.net

23. Yadav IS, Yadava TP, Kumar D (1988) Identification of parents for hybridization through combining ability analysis in Brassica campestris L. var brown sarson. In: Proceedings of the 7th international Rapeseed Congress, Poland pp 317-324

24. Zhao J, Becker HC (1998) Genetic variation in Chinese and European oilseed rape (B. napus) and turnip rape (B. campestris) analysed with isozymes. Acta Agron Sin 24:213-220

25. Zhao J, Wang X, Deng B, Lou P, Wu J, Sun R, Xu Z, Vromans J, Koornneef M, Bonnema G (2005) Genetic relationships within Brassica rapa as inferred from AFLP fingerprints. Theor Appl Genet 110:1301-131 